\title{
Communication Between Midwives and Women-in-Labour: A Case Study of Mamprobi Polyclinic-Accra, Ghana
}

\begin{abstract}
Gloria Baffoe
\section{Abstract}

The quality of communication between the midwife and women who are in labour is important in midwifery care. The study sought to investigate the communication between midwives and women-in-labour at the Mamprobi Polyclinic in the Greater Accra Region of Ghana. Being a qualitative study set on a bedrock of a case study design, the main focus was to obtain rich insights into how they communicate during the labour process. Using Rhetorical Sensitivity and the Interaction-Process analysis theories, a total of 6 women-in-labour and 2 midwives participated in the study. The findings from the study revealed that midwives used diversion therapy to ward client's minds off excruciating labour pains. They also used proxies and gestures to relay information to clients in cases where they were confronted with communication challenges. Women-in-labour were also counselled on self-care and care of baby while open and close-ended questions were used by midwives to elicit information from women in order to provide optimal care. Both verbal and nonverbal means of communication were used by women-in-labour to convey messages to midwives for medical attention. What emerged seemed to suggest that abusive communicative behaviour was predominant in the labour ward. However, midwives consider their communicative behaviours as preventive measures that facilitate safe delivery.
\end{abstract}

Keywords: midwifery care, labour, Ghana

DOI: $10.7176 / \mathrm{NMMC} / 84-02$

Publication date:October $31^{\text {st }} 2019$

\subsection{Introduction}

Child bearing, being a psychosocial event has a lot of influence on the woman and for that matter makes the delivery process a critical aspect of maternal care (Simkin, 1992). The midwife recognised as one who supports women to give birth is considered an important personality whose relationship with the woman is a pertinent issue in child delivery. It is a time that women also envision that there will be effective information sharing in the labour ward that will make them have a feel of sense of belongingness and safe birth.

Walsh and Downe (2004) echo these expectations of child bearing women stating that key issues for women are having a safe birth, developing supportive relationship with their caregivers and being treated with dignity and respect. Effective communication is therefore vital in maternal care because poor support and communication during labour and birth is associated with a higher rate of postnatal mental health problems including postnatal depression and post-traumatic stress disorder (Creedy, Shochet, \& Horsfall, 2000; Czarnocka \& Slade, 2000; Lemola, Stadlmayr, \& Grob, 2007).

Again, the ability to effectively communicate is an essential life skill that becomes a prerogative for every midwife due to the processes involved. According to Keyton (2011) communication is defined as the process of transmitting common understanding from one person to another. This definition brings to bare that unless both participants in the communication process understand each other, there is no communication. Knowing that bringing another human being into the world is an important process, good communication skills become essential especially, in the labour ward, where a lot of communications go on between the midwives and women to make the child delivery process either a smooth one or otherwise.

Dickson (1997) emphasised that caring in midwifery services is the best way for women to have positive birth experience and that the presence of a midwife, her communication skills, knowledge and understanding are critical factors. Hence the voices of women should be listened and responded to, in order to assure them of safe delivery. A high -quality maternal system should be put in place to provide optimal maternity care that follows the principle of "effective care with least harm" that supports the beneficial practices that support women's own capacities or psychological process of child birth (Sandall, 1998).

Evidence-based studies show that effective interpersonal and communication skills are associated with improved health and outcomes (Stewart,1995; Stewart et al, 1999). In effect, effective communication should be championed in the labour ward to achieve positive results. Howarth, Swain and Treharne (2011) reiterate this by stating that the relationship built with the woman and the atmosphere created by the midwife's presence is the key to positive experience.

Some studies have been conducted to establish how quality of relationship and care, are of essence and fundamental to a woman's birth experience. For example, Hodnette (2002), in her important systematic review of 137 research studies, exploring women's experience of birth, pinpointed four (4) key factors that were very vital in their estimation of their birth experience. Two of these factors directly relate to relationships: the quality of the woman/caregiver relationship and the amount of support received from caregivers.

Furthermore, studies conducted by Nilsson and Lundgren (2008) show that the fear of childbirth is often the 
result of previous negative experiences of care, and that quality of relationships with caregivers is central to these experiences.

There has been rare investigation into the communication relationship between midwives and women-inlabour. This study therefore is to investigate communication between midwives and women-in-labour at the Mamprobi Polyclinic, Accra, Ghana with much focus on the interactions that exist between them and how this affect quality care. Hence by embarking on a case study with midwives and women-in-labour as the lens, this dissertation seeks to generate insight into how this phenomenon actually occurs in the Polyclinic.

\subsection{Objectives of the study}

This research seeks to achieve the following objectives:

1. To identify how midwives communicate with women at the Mamprobi Polyclinic.

2. To verify how women communicate with midwives at the Mamprobi Polyclinic.

3. To analyse the interactions that occur between the midwives and women-in-labour at the Mamprobi Polyclinic.

\subsection{Method of data collection}

A qualitative research approach and a case study design were adopted for this research. In this study the target population included all midwives who have practiced for many or few years in the Mamprobi Polyclinic and women-in-labour who have given or not given birth before, in the same clinic in Accra during the period of study. A non-probability sampling technique was used to select participants for the study.

Gay, Mills and Airasian (2009) explain that qualitative sampling involves the selection of participants for a study in a manner that the individuals chosen would be key informants or respondents who would contribute to the researcher's understanding of a given phenomenon. In so doing, purposive sampling was adopted. In all, 8 participants, 6 women from the labour ward and 2 midwives, participated in this study.

The researcher collected and analysed data through participant observation and interviews from November, 2015 to January, 2016. Data was first collected from women in the labour ward and the lying ward the same day permission was granted to the labour ward. However, four visits were made to the ward to get accurate information on how midwives and women-in-labour communicated in the labour ward. Observations lasted from one to two hours. Other dates were set for follow up interviews with the women after they were discharged from the Clinic. During the interview open-ended questions which required deeper responses from the interviewees were posed. The interviews with the midwives and the women also lasted 10 to 15 minutes. All interviews were conducted with the aid of an interview guide. Most of the respondents were visited once. Only a few of them were visited twice because the researcher wanted more clarifications from them after some observations.

The interviews were recorded with the recording application on the mobile phone of the researcher and were played back over and over again before finally employing the service of a professional translator to transcribe those responses in the local languages verbatim in English. It is however, only the midwives who preferred responding to questions in English.

\subsection{Data Analysis and Procedure}

Relevant issues or ideas that emerged from firsthand information obtained from the labour ward and the transcription from the recorded interviews were coded according to the consistent similarities of ideas that emerged and various themes drawn out of the responses were developed for discussion.

\subsection{Findings and Discussion}

\subsubsection{The use of diversion therapy}

The observations made in the ward revealed scenarios of women going through painful contractions and their inability to sometimes hold the pain. The midwives use of diversion therapy in the labour ward to take the minds of women off labour stress or to reduce pain and anxiety in them indicated or communicated to the women that they shared in their pain and stress. And this is in line with what Bales (1950) suggests in one of his concepts, dramatizing, in his Interaction-Process Analysis theory which highlights the use of jokes as a means of provoking a laugh to release tension. During the interview with the midwives they explained the importance of the diversion therapy to the women. This is what the first midwife said:

Sometimes you realize that they are in severe pains and you can't do anything than to show empathy. This is when we create jokes to divert their attention and some of them even don't laugh when they are in severe pain. It is after delivery that they will see you and start laughing, they now remember what you tried doing and they didn't mind you (Midwife 1).

Empathy comprises of being able to accurately understand and appreciate the feeling, and experiences of the woman the midwife is caring for as well as making the understanding evident for the woman so that she feels understood and accepted (Freeth 2007; Stuart, 2009). The second midwife in sharing her view also revealed that sometimes when they see women wallow in labour pains they themselves become stressed but they manage to 
hide their stress and reach out to them to reassure them. This is what she also said:

Sometimes we just stand by the patients talking to them just to divert their attention from the pain and to reassure them that they will be fine. We let them know that the more severe the pain is the more the baby comes out. We could even have done better if our set up was good by allowing their husbands to be with them during the second stage (Midwife 2).

The way a woman is treated by the professional on whom she depends may largely determine how she feels about the experience for the rest of her life (Simkin, 1992). It was unearthed during the interview with the women that they were satisfied with the sense of urgency the midwives exhibited in administering diversion therapy when necessary especially during the second stage of labour which urged them to give birth. To them this action indicated that they were in safe hands so they should be in control of the process. The following statements supported this revelation:

But the midwives who helped me to give birth were good. Aside guiding me on what to do, one of who was constantly fanning me urged me to give birth. I heard her saying "sweetheart have you seen how I am fanning you? Look at that and give birth" and that alone was enough (Respondent, 5).

The willingness of the midwives to use every communicative means possible to divert their attention from the excruciating pain as a form of an assurance of presence and safe delivery, according to Natukunda (2007) is a positive communicative behaviour and essential in the delivery of a healthy mother and a live baby.

\subsubsection{Predominance of abusive communicative behavior}

Wilkins (2002) states that cordial communicative relationship between midwives and women during labour is very important and will enhance positive outcome. Careful observations from the ward and findings from the interview conducted revealed that midwives sometimes not only communicated rudely to women but physically abused them. The women revealed that midwives rudely interrupted them anytime they sought opinion from them. For instance, the $3^{\text {rd }}$ respondent said:

Anytime I contracted more I went to ask them whether I should go to the labour room because I felt the baby was coming and that was when they insulted me and said "am I the midwife to know whether my baby was coming out or not (Respondent 3 ).

According to Jacelon (2002) the dignity of a patient may be threatened if the midwife's communicative behaviour sounds authoritative. The importance of ensuring the dignity of patients has necessitated the campaign for the need to institute patients' rights. In the United Kingdom for instance, there is increasing emphasis on patients' rights to be treated with dignity (Department of Health, 2006) because studies indicate that nurses have been relating poorly to patients in ways that affect their dignity such as ignoring patients and talking to patients in harsh manner (Calnan, Dieppe, Tadd \& Woodhead, 2005). The disappointment shared by some of the women in the ward about the manner in which they were talked to is illustrated below:

I felt bad whenever I went to them and they told me to go back I asked myself this question several times whether they didn't like me. I felt I should insult them back but I stopped because I felt they will neglect me if I confronted them. (Respondent 6).

The Government Select Committee report (known as the Winterton report) highlights that women cite the importance of having choice and control when using maternity services. Findings revealed that the women wanted choice and control especially during vaginal examination and during child delivery. They preferred that during continuous and painful contractions, they were left alone without undergoing any examination. The painful experience prevented them from being absolutely cooperative, a situation that infuriated the midwives who in turn verbally and physically abused them. Below are the statements from some respondents:

When I get up they shout at me to lie down. When I couldn't open my legs wide they screamed at me and slapped my thighs. One midwife even said when I was doing the thing I was happy and now I can't open my legs (Respondent 4).

There was a time I became fed up. Ah... one person about five people kept on examining me and they kept on screaming at me anytime it became painful and I couldn't open my thighs wide (Respondent 8).

These statements from respondents were not different from what has been reviewed in literature. A qualitative study using Focus group discussions with women and men including health staff to determine perceptions of delivery care in Nigeria, Asuquo et al (2000) revealed that majority of the women in four groups in two communities abhorred the communicative behaviour of hospital staff toward patients stating rudeness, shouting and scolding as instances. Even though the women in Mamprobi Polyclinic viewed scolding and shouting as abusive communicative behaviour, the midwives viewed their actions from a different lens. First of all, they admitted to the claims of the women. However, they equated their actions to being firm but not abusive. Their reason was to avoid the complication of losing the mother or the baby and eventually facing disciplinary actions.

Their style of reducing problems in the ward is not far-fetched from Snyder (1974) and Hart, Carlson and 
Eadie (1980) whose description indicate that noble self-communicators who consider themselves as low selfmonitors communicate in ways that fit their own needs with little or no attention to other people. So in order not to suffer the pain of losing the mother or the baby, they preferred not to pamper her but to communicate in ways that would bring best outcomes. Here are what the $2^{\text {nd }}$ midwife voiced:

Sometimes if the head of the baby is low, they say they want to visit the lavatory. The cervix might not be fluid and they start to push. When you tell them to stop and breathe through their mouth some will do, others will remain stubborn, that is the only situation you see a midwife will beat or verbally abuse a client and it is mostly in the second stage (Midwife 2).

Rising to another defense on predominant communicative behaviour in the labour ward, the $2^{\text {nd }}$ midwife interviewed, declared that sometimes they rid themselves of sympathy so that it will not impair their ability to care for the patient. The midwife said that because the process of pushing baby out during the second stage is stressful and painful, women do relax to catch up breath. Wrong timing of doing so may result to complications due to the position of the baby at that critical time. Thus, for them not to be swayed by emotions, they sometimes apply harsh mechanisms to stop any hitch. Hear what she said:

As for me when they prove stubborn during the second stage, I hold their nose for few seconds to communicate to them that that is what the baby is going through so if they don't push the baby will die. No midwife will wish to go for auditing after delivery to be finally told that she is responsible for a mother or baby's death. So, we become harsh sometimes (Midwife 1).

\subsubsection{Midwives' relationship with women in the labour ward}

Waldenstrom et al (2004) and Nilsson and Lundgren (2008) state that a woman's fear of child birth is often as a result of previous negative experiences and an important factor is a lack of quality in the relationship with care givers.

During data collection, the women revealed they feared being mistreated even prior to their visit to the labour ward. This is exemplified in the statement below:

Sometimes I became scared that when I go there they will do me "Hey! Hey! Hey!" they will do you something that you don't like and when you fight back they might not treat you well even though we all pay the same tax to the government (respondent 5).

Undoubtedly, the women revealed their fears were confirmed by the harsh manner the midwives communicated to them. They minced no words by showing disapproval to the researcher during the interview. But they disclosed that in the labor ward they couldn't demonstrate their discontent. According to Motley (1992) a communicator is consciously aware of his communication decision and adapts his communication to the situation. These women adapted the communication style of keeping mute in the labour ward due to their intense state of vulnerability and also due to the fact that their exhibition of resentment would lead to them being unattended to or isolated. This was what the $4^{\text {th }}$ respondent voiced:

I became afraid because she kept on telling me she would take me to Korle-bu if I don't cooperate. What if I lose my baby so I quickly had to give birth and leave the premises (respondent 4).

According to Kettunen, Poskiparta and Gerlander (2002) the nurse-patient relationship is founded on power relations. Nurses rely on their professional knowledge and show their power through controlling information, questioning and rewarding. Patients also perceive that their power is in their demand for the services of nurses. And that readies the stage for power struggle that eventually affects their relationship. Dwelling on the relationship between the midwives and the women, those women who believed that the task of the midwives were to give them quality care devoid of intimidation expressed their dismay at their communication style. This is demonstrated in the response of the $6^{\text {th }}$ interviewee:

I had every right to tell them to tone down on me but I was afraid to tell them. But they should know that we are all human beings. They have given birth before. If they had it easy it is not everybody who will have it easy (respondent 6).

It is an obvious fact from the statements by the respondents that they expected their care givers to develop a communicative relationship with them and treat them with dignity and respect.

\subsubsection{Lack of continuous communication with women-in-labour}

Women have better outcome and a decrease in labour when they have a supportive person with them during labour (Family Care International, 2002). According to Magee and Askham (2007) women view care as unsafe when they are left alone and worried or when they do not know who is looking after them or are not receiving the full attention of their midwife.

During observation in the ward, it was realised that the midwives' attention to the needs of the women seemed to be based on their own understanding of care during labour and on their own experience of child birth. They paid attention toward writing reports, planning and having vaginal examination or when the next vaginal examination would be performed. However, there were few times a midwife was seen talking to some of the women and even that, it was due to persistent calls from the women. 
During the interview session with the women, they equally confirmed that there were moments they expected the midwives to show continuous support to them by talking to them and calming them down but didn't experience as expected. Their views are exemplified below:

When I was lying there in pain and screaming, I thought they would come around but anytime they heard me scream they asked me to shut up and said they were sure after giving birth to my child I will not hesitate to get pregnant again. That was uncalled for (respondent 3).

A review of literature by Scandinavian researchers Johansson, Oleni and Fridlund (2002) indicated that patients' satisfaction with care is influenced by interpersonal relations between the nurses and the patients. For the women in the labour ward, good characteristics of midwifery were to be attentive, empathetic, to be available and reassuring as suggested by Davis (2005) and not what they witnessed. Here is what this respondent disclosed: ...none of them came to reassure me that it would be okay. When they came around too they only came to check whether the cervix had dilated and left (respondent 4).

Midwives are supposed to be involved in labour processes from the beginning to the end. Under involvement behaviour such as distancing, disinterest, coldness and neglect is likely to be detrimental to the woman and the infant (A midwife's guide to professional boundaries, 2010).

Even though it was revealed through observation in the ward and through interview with the women-inlabour that midwives did not constantly communicate with them by showing continuous support, midwives vehemently opposed this assertion when it was their turn to share their views. One of them said:

They are lying! Oh mothers! As you can see we have opened our curtains. We have been going there monitoring them till they deliver. Sometimes we ask them what is wrong with them. Have you eaten? Drink more water. Relax so that when the baby is coming you can push (Midwife 1).

The midwives continually argued that they could not constantly be with the women. They revealed that usually after the first vaginal examination, the next one is done in four hours later and because the women were not privy to this information, they assumed that anytime they complained the midwives should be with them.

As it has been reviewed in the literature by McCourt et al (2006) who indicate that women describe the importance of knowing their midwives particularly, during labour and birth and the confidence and trust it brings, the comments from women about lack of continuous communication from midwives undeniably, reveal that women view communication relationship with their maternal health care givers as important. Likewise, Freely (1995) describes the importance of communication relationship stating that midwives can do a better job by becoming acquainted with their patients and taking responsibility for them. The creation of a communicative relationship will enable women to be in control and help in the support of physiological birth in the comforting role of the midwife.

\subsubsection{Counselling for women in the labour ward}

A concept of Bales (1950) Interaction-Process Analyses theory lay emphasis on giving suggestions to individuals while accomplishing a given task. In this category, there are direct attempts to guide or counsel or prepare another member by prevailing upon him or her to perform an action. The findings of this study revealed that the midwives in the labour ward often gave suggestions to the women in the ward either during the first or second stage of labour or after birth.

The women were most times guided on how to position themselves on their various beds to enable babies in the womb get enough oxygen. According to the midwives, usually during contraction when the women lie on their right, labour pains decreases. Due to that they mostly enjoy lying on their right so as to alleviate the pain. However contrary to their idea of lying on their right, the women fail to recognise that by doing so they prevent their babies in the womb from getting enough oxygen. So, the suggestions given to the women by the midwives to lie on their left if followed, bring relief to the babies. This is what one of the midwives said:

When there is contraction, oxygen supply to the baby is ceased or reduced and the baby does not get enough oxygen. So normally, we suggest to the women to lie on their left which is really not comfortable and breathe through their mouth to get enough oxygen for the baby (Midwife 1).

The midwives further revealed that the women were also sometimes advised to have warm bath while in the ward to ease labour stress. During child birth too, women were also guided on how to push baby out. For example, they were told to take deep breath and push baby out when contractions became severe. To add to that, when the women failed to communicate to midwives about the kind of diseases such as sexually transmitted diseases they had contracted during antenatal care and they were detected during labour, they were given guidelines in order to prevent them from spreading to their babies. In these instances, the midwives suggested to the women the type of drugs they should buy so that they would be administered to their babies. For mothers with the Hepatitis "B", the midwives suggested to them to take the Hepatitis "B" injection right after birth before the babies were breast fed.

The midwives again revealed that they suggested to women the various types of birth plan available for 
them to adopt after birth before they went to the postnatal ward for further counselling. With this particular counselling, I observed several times being done while in the ward. This finding is in line with the statement of Rudy, Tabubutt-Henry, Schaefer and McQuide (2003 p.3) that "informed choice is a logical outcome of effective Client Provider Interaction (CPI) because good CPI gives client the information that they need to make sound decisions along with help considering their options". Giving information in a form of suggestions is vital and helps both the midwives and the women in the ward achieve good results.

\subsubsection{Verbal and nonverbal forms of communicating}

Verbal communication takes place when people use words to share experiences with others. Without the use of spoken language, individuals are severely limited in the means of sharing with others what they are feeling (Arnold \& Boggs, 2007). Investigations into the study unearthed women usually used verbal communication to draw the attention of midwives to administer the necessary support or care to them. For instance, it was observed that women normally called midwives to their various beds any time they wanted something to be explained to them and by that the midwives were able to offer the needed help to them.

Apart from verbal communication, various visible signs or nonverbal cues which according to Ellis et al (1997) and Roberts and Bucksey (2007) involve all forms of communication other than spoken, were exhibited during labour by the women in the ward. The midwives revealed during the interview with the researcher that these nonverbal cues communicated to them in several ways for them to render the required medical attention as and when labour progressed.

As Hart, Carlson and Eadie (1980) portray that a Rhetorical sensitive person thinks about what message should be sent and how it should be relayed to the listener, the following nonverbal cues portrayed by the women according to the midwives, communicated in diverse ways to them:

1. When women were seen clutching their beds and stretching most times, it meant labour was progressing steadily so she, the midwife, would have to touch the woman's abdomen to see if it was hard. If it was, it signified to her that her assumption of labour progression was correct hence didn't have to worry much about the woman.

2. When women sweat profusely, it meant labour was active and was reaching the second stage.

3. Again when women asked for more water, it meant they were dehydrated. Therefore, they needed to be hydrated by giving fluid which could be either water, juice, or intravenous infusion.

4. Moreover, in the second stage of labour when women are unable to push baby out despite very strong and frequent contraction, it communicated to them that there was a problem which needed immediate attention.

5. Frequent urination also communicated to them that the head of the baby of woman was descending and for that matter baby would be out soon. So the labour room should be made ready for the woman.

6. Last but not least, when women were seen defecating on themselves, it meant the baby's head was exerting much pressure on the anus. Thus, an indication that the cervix had fully dilated for the baby to come out so they should be sent to the delivery room to give birth.

In the Rhetorical sensitivity theory, Spitzberg and Cupach (1984) postulate that a critical feature in effectively communicating is a person's ability to reflect and adapt his or her communication behaviour as the situation changes. Thus, the midwives revealed that the nonverbal cues exhibited by the women were important because they communicated to them how they should adapt to the changes seen in them and administer the requisite medical attention.

\subsubsection{Rhetorical and Reciprocal Exchanges.}

The interaction between the health care provider and patients in a health facility usually takes question and answer format with the goal of exchanging information to resolve a medical problem (Sharf, 1990). In the labour ward it was revealed that midwives mainly used questions and answer format to generate different types of information from women. According to Cegala (1997) effective exchange of information between health care provider and patients occurs in these dimensions: information seeking, information giving and information verifying. Information seeking is the use of communicative behaviours, specifically, the use of closed and openended questions by health care providers to connect with their patients.

Findings revealed that anytime the women entered the labour ward, midwives after heartily welcoming them first of all, read through their antenatal books to familiarise themselves with the report inside. They followed this action with open and closed-ended questions to verify the real state of the woman so as to offer treatment after. This is what a midwife revealed:

Some don't know what is real labour so you ask what is wrong with them, whether they have seen blood or some fluid or their water had broken and would want to share with us and so on and so forth (Midwife 2).

The kind of answers the women gave according to the midwives, communicated to them whether it was a 
case of true or false labour or it was a gynecological case or whether it was a normal sickness which should be transferred to the Out-Patient-Ward to enable a doctor attend to her.

However, if they were certain that it was true labour, they offered the required treatment. For instance, the women were made to undergo vaginal examination to determine how the cervix had dilated. Interviews with the women confirmed this revelation. The $6^{\text {th }}$ respondent interviewed said:

After the ' $\mathrm{V}$ ' examination, I was told that the cervix had not dilated so I should go back home to either have sex with my husband or to eat okra stew to aid my delivery (Respondent 6).

But with that of the $4^{\text {th }}$ respondent she disclosed that she had given birth before and for that matter knew the signs of true labour so after spotting one or two signs her family members quickly rushed her to the hospital.

She said:

She examined me and said labour was progressing smoothly so I should lie down for a while because I could deliver my baby any time soon (respondent 4).

The medical treatment given by midwives to the women after questioning is in line with the statement of Cegala (1997) who indicates that information verifying increases the understanding of all parties involved. Furthermore, the questioning and answer chitchat between patients and midwives that enabled information to be derived so that proper administration of medical care was given endorses what Bales (1950) suggests in his theory that in accomplishing tasks, individuals ask for information and by that they get an answer that could be judged as true or false on the bases of simple observation or an answer that is generally regarded as an empirical fact.

\subsubsection{The use of proxies and gestures to communicate}

According to Imberti (2007) language is our greatest mediator that allows people to relate and understand each other. In the context of communication, language is linked to culture because it identifies individuals (Lauring, 2008). It however becomes a challenge when individuals especially in the health setting are not able to communicate effectively to comprehend the content of the conversation. Braser and Fraser (2000) Collins et al (2002) and Denboba et al (1998) proffer that communication barriers related to cultural and linguistic diversity are increasingly recognised as contributors to health disparities between patient groups thus it is important to recognise the diversity with language groups when thinking about language barriers between patients and health care deliverers.

Findings revealed that language barrier was prevalent in the facility due to its location. Patients with different linguistic background patronised the Clinic for maternal health care. The midwives interviewed disclosed that communication sometimes became challenging while accomplishing tasks in the labour ward. This is exemplified below:

I speak Twi and there are a number of midwives who speak Twi here although those who speak Ga dominate. Most times it becomes difficult when I meet clients who don't speak my language. I do ask for midwives or other people who speak same language to help in times like that (Midwife 2).

Communication barriers may affect the sharing of opinions, the giving of suggestions and information due to the cultural background of the individual. Hence the manner in which messages are interpreted is important particularly where safety is concerned (Crilly et al, 2008). This midwife whose comment is demonstrated below revealed that she had on some occasions encountered situations where she felt handicapped in relaying information to clients, thus had to fall on proxies or use gestures. She recounted:

Many people with different languages come here. We have Northerners, Nigerians, Fantes, Twi, Gas, Ayigbe. Everybody comes here. When I am deficient in the language my client speaks and I don't get any one to help, I use gestures to help the client deliver her baby (Midwife 1).

Fortunately, on that same day this interview took place, an experience of such had happened so the midwife directed one of the patients who acted as proxy to also share her experience. She revealed that she spoke Hausa so she alerted the midwives when she realised they were having difficulty in helping the woman to give birth. Gradually, the woman gave birth and she also helped to explain to her what the midwives wanted her to do after delivery.

This endorses what Hornberger et al (1996, p.846) describe, "the clinician should communicate to the proxy to learn the patients' problems, needs and concerns and to convey information and offer recommendations about care".

An effective communication should enable both the midwife and the woman in the labour ward, understand the content of each other's spoken communication, feel that they are rightly understood by each other, leaving no thoughts and questions unexpressed and feeling satisfied with the communication to achieve optimal quality care.

\subsection{Conclusion}

This study investigated the communication between midwives and women-in-labour at the Mamprobi Polyclinic. 
The study concluded that while accomplishing the task of bringing another being into the world, both midwives and women-in-labour engage in a lot of communications. In that, during the process of labour and child delivery, they both give information, ask for information, opinions and give suggestions to facilitate quality and safe maternal care. Again, in order not to convey any negative messages that might affect the smooth delivery of the process, both midwives and women-in-labour are conscious of their communicative decisions and adapt their communications to situations as and when they occur in the labour ward.

Even though most women attest to the fact that abusive communicative behaviour is predominant in the labour ward, midwives nonetheless, consider their communicative behaviour as preventive measures they consciously adopt (Motley, 1992) to facilitate safe delivery.

While women-in-labour complained of lack of continuous communication relationship with midwives during their stay in the labour ward, midwives on the other hand refused this claim on grounds that it was their continuous communication relationship with them that enabled them to detect cases for referrals.

The community that the facility is located, houses people from different cultural backgrounds. Thus language barrier which is a challenge sometimes leads to ineffective communication between midwives and women in the labour ward.

It is also remarkable to note that the sense of urgency by midwives to administer diversion therapy on women to distract them from excruciating labour pains was greeted with much satisfaction by the women-inlabour who deemed the action as a life time experience they will live with (Simkin, 1992)

\section{References}

A midwife's guide to professional boundaries, (2010). Retrieved from $\mathrm{http} / /$ :www.nursingmidwiferyboard.gov.au.

Arnold, E., Underman-Boggs, K. (2007). Interpersonal Relationships: Professional Communication skills for Nurses, 5th ed. Saunders St Louis, MO.

Asuquo, E., E., J., Etuk, S., J., \& Duke, F., (2000). Staff attitude as barrier to the utilization of University of Calabar Teaching Hospital for Obstetric care. African Journal of Reproductive Health: 4(2) 69-73 doi: $10.2307 / 3583450$

Asuquo, E., E., J., Etuk, S., J., \& Duke, F. (2000). Staff attitude as barrier to the utilization of University of Calabar Teaching Hospital for Obstetric care. African Journal of Reproductive Health 4(2), 69-73 doi: $10.2307 / 3583450$.

Berg, M., Hunter, Kirkam, M., Lundgren, I., \& Olafsdottir, O. (2008). Relationships: the hidden threads in the tapestry of maternity care. Midwifery, 24, 132-137.

Brach, C., Fraser, I., (2000). Can Cultural Competency Reduce Racial and Ethnic Disparities? A Review and Conceptual Model. Medical Care Research and Review 57, 181-217.

Calnan, M., Woodhead, G., Dieppe, P., \& Tadd, W. (2005). View on dignity in providing health care for older people. Nursing Time 101(33), 38-41.

Cegala, D., J. (1997). A study of doctors' and patients' communication during a primary care consultation: Implications for communication training. Journal of Health communication (2), 169-194.

Creedy, D., Shochet, I., \& Horsfall, J. (2000). Childbirth and the development of acute trauma symptoms: Incidence and contributing factors. Birth 27(2), 104-111.

Crilly, N., Good, D., Matravers, D., \& Clarkson, J., P. (2008). Design as communication: Exploring the validity and utility of relating intention to interpretation. Design Studies, 29, (5), 425-457.

Collins K., S., Hughes, D., L., Doty, M., M., Ives, B., L., Edwards J., N., \& Tenny, K. (2002). Diverse, Communities, Common Concerns: Assessing Health Care Quality for minority Americans. Findings from Commonwealth fund 2001 Health Care Quality Survey. New York: Commonwealth fund.

Davis, L., A. (2005). A phenomenological study of patients' expectations concerning nursing care. Holistic Nursing Practice. (19), 126-133.

Dawson, R., Hancock, B, A. (2011). Doing Case Study Research: A Practical Guide for Beginning Researchers, (2nd ed.). Amsterdam Avenue, New York, NY: Teachers College Press.

Department of Health, (2006). A New Ambition for Old Age: Next steps in Implementing the National Service Framework for Older.

Downe., S. (2008). Normal child birth: Evidence and debate, (2nd ed.) Churchill Livingstone, Edinburgh: New York.

Ellis, R., B., Gates, B., \& Kenworthy, N. (2006). Interpersonal Communication in Nursing, (2nd ed). Churchill Livingstone, Edinburgh.

Family Care International (2002). Retrieved from www.familycareintl.org/en/home.

Freely, M. (1995). Team midwifery a personal experience. In: page L(ed.). Effective group practice in midwifery: working with women. 3-11. Oxford: Blackwell Science.

Freeth, R., (2007). Humanising Psychiatry and Mental Health care. The challenge of the person-centered 
Approach. Oxford. Radcliff Publishing.

Gay, L., R., Mills, G., E., \& Airasian, P. (2009). Educational Research: Competencies for Analysis and Application (9th Edition). Upper Saddle River NJ: Merril/ Pearson Education Inc.

Hancock, B. (2002). Trent Focus for Research and Development in Primary Healthcare: An Introduction to Qualitative Research. Trent Focus.

Hart, R., P., Eadie, W., F., \& Carlson, R., E. (1980). Attitude toward communication and the assessment of rhetorical sensitivity. Communication Monographs (47), 1-22.

Hart, R., P., \& Burks, D., M., (1972). Rhetorical sensitivity and social interaction: Speech Monographs 39(2), $75-91$.

Hayford, S., K., (2013). Special Educational Need and Quality Education for All. Winneba: Department of Special Education Books.

Hodnette, E., (2002). Pain and women's satisfaction with the experience of child birth: a systematic review. American Journal of Obstetrics and Gynecology. 186.

Holloway, L., (2005). Basic concepts of qualitative research. Oxford: Blackwell Science.

Hornberger, J., C., Gibson, C., D., Wood, W., Dequueldre, C., Corso, I., Palla, B., \& Bloch, (1996). Eliminating Language: Barriers for Non-English-Speaking: Patients Medical Care 34(8), 845-856.

Howarth, A., Swain, N., \& Treharne, G., J. (2011). New Zealand mothers' experience of birth: Importance of relationship and support. New Zealand College of Midwives Journal (45), 6-11.

Hunter, B. (2006). The importance of reciprocity in relationship between community-based midwives and mothers', Midwifery Journal 22(4), 308-322. $\quad$ Retrieved from http://dx.doi.org/10.1016/j.midw.2005.11.002,PMid:16616398.

Imberti, P. (2007). Who resides behind the words? Exploring and understanding the language experience of the non-English speaking immigrant. Families in Society, 88(1), 67-73.

International Confederation of Midwives (2005). Definition of the midwife. ICM, FIGO, WHO. Retrieved from www.internationalmidwives.org.

Jacelon, C., S., (2002). Attitude and behaviour of staff towards elders in an acute care setting. Journal on Applied Nursing Research (15) 227-234.

Johansson, P., Oleni, M., \& Fridlund, B. (2002). Patient satisfaction with nursing care in the context of Health care: a literature study. Scandanavian Journal of Caring Science, (16) 337-344.

Kettunen, T., Poskiparta, M., \& Gerlander, M. (2002). Nurse-patient power relationship: Preliminary evidence patients' power messages. Patient Educational and Counselling, (47), 101-113.

Keyton, J. (2011). Communication and organizational culture: A key to understanding work experience. Thousand Oaks, CA: Sage.

Lauring, J., (2008). Rethinking social identity theory in international making. International Journal of Cross Cultural Management (8) 343.

MacCourt, C., Stevens, T., \& Sandall, J., et al, (2006). Working with women, developing continuity of care in practice. In: Page LA, McCandlish R (eds.). The new midwifery: Science and sensitivity in Practice, (2nd ed.). Churchill Livingstone, Edinburgh.

Magee, H., \& Askham, J. (2007). Women's views about the safety in maternity care: a qualitative study. Kings Fund London.

Motley, M., T., (1992). Mindfulness is solving communicators' dilemas. Communications Monographs, (59), 306-314.

Natukunda, C., (2007). Midwifery Behaviour and Practice. Accra: Mikono Publishers.

Nilsson, C., \& Lundgren, I., (2008). Women's lived experience of fear of childbirth: Midwifery in press. Doi:10.1016/j.midw.2007.01.017.

Roberts, L., Bucksey, S., J. (2007). Communicating with patients: what happens in practice? Physical Therapy $87(5), 586-594$

Rudy, S., Tabbutt-Henry, J., Schaefer, L., McQuide, (2003). Improving Client-Provider Interaction. Population Reports Q.I. Johns Hopkins Bloomberg School of Public Health, the INFO, Project, Baltimore.

Sandall, J. (1998). Occupational burnout in midwives: new ways of working and the relationship between organisational factors and psychological health and well-being. Risk, Decision and Policy 3(3), 213-32.

Sharf, B., F. (1990). Physician-patient communication as interpersonal rhetoric: A narrative approach. Health Communication, 2(4), 217-231.

Simkin, P. (1992). Just another day in a woman's life? Part II: Nature and consistency of women's long-term memories of their first birth experiences. Birth, (19), 64-81.

Spitzberg, B., H., \& Cupach, W., R. (1984). International Communication Competence. Beverly Hills, CA: Sage. Snyder, M. (1974). Self-monitoring of expressive behaviour. Journal of Personality and Social Psychology, $30(4), 526-537$.

Stewart, M. A. (1995) Effective physician-patient communication and health outcomes: a review, Canadian 
Medical Association Journal, (152), 1423-1433.

Stewart, M., Brown, J.B., Boon, H., Galadja, J., Meredith, L. \& Sangster, M. (1999) Evidence on patient-doctor communication, Cancer Prevention and Control, (2), 25-30.

Waldenstrom, U., Hildingsson, I., Rubertsson, C., Radestad, I. (2004). A negative birth experience: Prevalence and risk factors in natural sample. Birth, (31), 17-27.

Walsh, D., \& Downe, S. (2004). Outcomes of free standing, midwife led birth centres: a structured review. Birth 31 (3), 222-229.

Wilkins, R. (2000). Poor relations: the paucity of the professional paradigm. In:Kirkham, M., (ed.). The midwifemother relationship. 28-52. MacMillan: London.

Wragg, T. (2000). Interviewing. In Colman, M., \& Briggs, A., R., J. (Eds). Research methods in educational leadership and management, 143-148. London: Continum. 